\title{
Características da Carcaça e Qualidade da Carne de Tourinhos Alimentados com Dietas de Alta Energia ${ }^{1}$
}

\author{
Fábio Garcia Ribeiro ${ }^{2}$, Paulo Roberto Leme ${ }^{3}$, Maria Luisa de Medeiros Bulle ${ }^{2}$, \\ César Gonçalves de Lima ${ }^{3}$, Saulo da Luz e Silva ${ }^{4}$, Angélica Simone Cravo Pereira ${ }^{5}$, \\ Dante Pazzanese Duarte Lanna 6
}

\begin{abstract}
RESUMO - Foram alimentados 36 tourinhos 3/4 Europeu $1 / 4$ Zebu com dietas contendo 9, 15 e 21\% de bagaço de cana-de-açúcar in natura (BIN) na matéria seca. Os animais, com peso inicial de $257 \mathrm{~kg}$, foram abatidos após 138 dias, com $435 \mathrm{~kg}$ de peso. Foram realizadas mensurações na carcaça e da composição física do corte das 9-10-1 1ª costelas. Amostras dos músculos Longissimus dorsi e Supraspinatus, maturadas durante 0,7 e 14 dias, foram analisadas quanto à textura e cor. A quantidade de gordura renal e pélvica foi maior para os tratamentos 9 e 15\% de BIN. Houve tendência para maior espessura de gordura subcutânea nos tratamentos 9 e $15 \%$ de BIN. Os diferentes níveis de fibra na dieta não alteraram a composição física e as características de carcaça, porém maior acúmulo de gordura nas regiões inguinal e pélvica foi observado em tratamentos com maior teor de concentrado. A textura objetiva (WB) apresentou diferença entre os três grupos de bifes maturados, nos dois músculos testados; o grupo com 14 dias de maturação foi mais macio que o tempo 7, e este, mais macio que o tempo 0 . Não foram encontradas diferenças entre os tratamentos nutricionais para a característica de cor, entretanto, houve efeito significativo para o período de maturação. A carne maturada (tempos 7 e 14) foi mais macia e brilhante, e suas cores, mais realçadas. A maturação teve grande impacto sobre a maciez em touros jovens produzindo carcaças de $230 \mathrm{~kg}$ e com 4 mm de espessura de gordura.
\end{abstract}

Palavras-chave: bovinos jovens, características de carcaça, composição corporal, confinamento, níveis de fibra

\section{Carcass Characteristics and Meat Quality of Young Bulls Fed High Concentrate Diets}

\begin{abstract}
Thirty six $3 / 4$ European $1 / 4$ Zebu bulls were fed diets containing 9,15 and $21 \%$ of the dry matter as sugar cane bagasse in natura (BIN). The animals, with initial body weight of $257 \mathrm{~kg}$, were slaughtered with $435 \mathrm{~kg}$, after 138 days on feed. Measurements in the carcass and the 9-10-11 th rib cut physical composition were taken. Samples of Longissimus dorsi and Supraspinatus muscles, aged 0,7 and 14 days, were analyzed for texture and color. Renal, pelvic and inguinal fat was higher for treatments with 9 and $15 \%$ of BIN. There was a tendency for greater backfat thickness in the treatments with 9 and 15\% of BIN. BIN level in the diets had no effect on physical composition or carcass characteristics. However, greater fat deposition in the inguinal and pelvic region was observed in treatments with greater energy. The objective texture (WB) was different with ageing in the two muscles, with greater tenderness after 14 days than after 7 , or 0 day. No significant differences in meat color were observed due to the BIN levels, but affected this characteristic. The aged steaks ( 0 and 14 days) were more tender and brilliant and their colors enhanced. Results suggest aging has great benefits on tenderness in young intact males with carcasses of $230 \mathrm{~kg}$ and $4 \mathrm{~mm}$ of fat thickness.
\end{abstract}

Key Words: body composition, carcass characteristics, feedlot, fiber levels, young bulls

\section{Introdução}

A utilização de dietas em confinamento com elevada proporção de concentrado fornecidas ad libitum é prática bastante comum na indústria de gado de corte norte-americana (Preston, 1998). Nos Estados Unidos, seis consultores em nutrição animal usaram níveis médios de $10 \%$ de volumosos em dietas para confinamento, num total de 3,6 milhões de cabeças confinadas anualmente nos Estados do
Texas, Nebraska, Novo México, Oklahoma e Kansas (Galyean, 1996). Esse manejo alimentar apresenta diversas vantagens, como a diminuição no tempo de terminação, devido, principalmente, à maior eficiência alimentar e ao elevado ganho de peso (Bulle et al., 1999).

De acordo com Preston (1998), essa forma de alimentação pode resultar em problemas digestivos para os bovinos, como aumento na produção de ácido láctico, diminuição no consumo, menores ganhos de

\footnotetext{
${ }^{1}$ Parte do trabalho de mestrado do primeiro autor.

2 Mestre em Zootecnia - Cx. Postal 23, Pirassununga,SP - CEP: 13.630-000. E.mail: fgarib@hotmail.com

3 Professor, Depto. Zootecnia, FZEA/USP. E.mail: prleme@usp.br

${ }^{4}$ Aluno de doutorado da FZEA/USP. E.mail: sauloluz@fzea.usp.br

${ }^{5}$ Aluna de mestrado da FZEA/USP. E.mail: ascpereira@hotmail.com

6 Professor, Depto. Zootecnia, ESALQ/USP, Bolsista CNPq. E.mail: dplanna@esalq.usp.br
} 
peso vivo, prejuízos nas paredes do rúmen e retículo, diminuição da função hepática e aparecimento de abcessos no fígado. Para evitar esses problemas seria necessário um processo gradativo, no qual níveis decrescentes de volumosos seriam fornecidos para uma melhor adaptação dos microorganismos do rúmen.

Bartle \& Preston (1991), Bartle \& Preston (1992b) e Bartle et al. (1994) compararam desempenho e características de carcaça de animais alimentados com diferentes níveis de volumoso. Os animais alimentados com restrição de volumoso ingeriram menos tiveram o mesmo ganho e tenderam a ser mais eficientes em relação ao grupo alimentado com $10 \%$ de volumoso. As carcaças tiveram melhor avaliação, e os custos com alimentação foram reduzidos, melhorando também a eficiência, a qualidade da carcaça e diminuindo o desperdício de alimentos.

Em condições normais de conservação, a cor é o principal atrativo dos alimentos (Felício, 1999). Ainda segundo o autor, a cor da carne "mostra" a quantidade e o estado químico da mioglobina $(\mathrm{Mb})$, seu pigmento mais importante. A quantidade de $\mathrm{Mb}$ nos cortes de carne bovina varia principalmente com o nível de atividade física dos músculos e a maturidade fisiológica do animal por ocasião do abate, sendo que alguns músculos são mais utilizados em relação a outros, motivo pelo qual apresentam numerosa quantidade de fibras vermelhas entre as fibras brancas, estas sempre em maior quantidade.

A cor da carne fresca é determinada pela proporção e pela distribuição de duas mioglobinas: a oximioglobina e a metamioglobina, sendo a oximioglobina vermelha, após a exposição do músculo ao oxigênio, a responsável pelo familiar frescor da carne (Seideman et al., 1984; Lawrie, 1985).

Felício (1999) citou que existem alguns métodos tradicionais para medir cor, e os colorímetros de uma maneira geral permitem que se façam boas leituras; os métodos mais conhecidos são o espaço ("color space") Yxy e os espaços L* a* b*. O espaço Yxy é baseado na teoria dos três componentes de visão de cor (vermelho, verde e azul) na qual as cores são vistas como a mistura dessas três cores primárias mas são de difícil interpretação. $O$ espaço $L^{*} a^{*} b^{*}$, também chamado de Cielab, foi desenvolvido por Cie (1976), sendo a metodologia mais utilizada em todas as áreas em que se necessita de medições de cor. Nesse espaço, o L* indica luminosidade, e o a* e o b* são as coordenadas de cromaticidade; o eixo que vai de $-a^{*}$ para $+a^{*}$ varia do verde ao vermelho, e o que vai de $-b^{*}$ para $+b^{*}$ varia do azul ao amarelo; quanto mais se "caminha" para as extremidades, maior a saturação de cor.

Diversos estudos têm mostrado que a maciez é uma das qualidades mais desejáveis na carne, do ponto de vista do consumidor, em relação a outras características qualitativas (Wellington \& Stouffer, 1959; Cia \& Corte, 1978; Felício, 1993; Koohmaraie et al., 1994; Luchiari Filho \& Moura, 1997).

Na moderna indústria da carne, a variação encontrada na maciez tem sido apontada como o principal problema na qualidade final do produto, segundo Koohmaraie et al. (1994). Koohmaraie et al. (1998) afirmam ainda que essa variação na maciez é devida a deficiências em produzir rotineiramente carcaças com carnes macias e também de identificar carcaças que irão produzir carne dura e classificá-las em seguida, segundo um padrão preestabelecido.

Uma das maneiras de atenuar o problema da maciez é o processo de maturação, que, de acordo com Felício (1997), pode melhorar em até 25\% a maciez da carne, diminuindo sua eficácia quando as carcaças forem de animais com mais de quatro anos ou que sofreram rigoroso "cold shortening".

Outro fator importante no produto carne é a sua coloração, que, na carne fresca, é determinada pela proporção e distribuição de duas mioglobinas, a oximioglobina e a metamioglobina, sendo a oximioglobina vermelha, após a exposição do músculo ao oxigênio, a responsável pelo familiar frescor da carne (Seideman et al., 1984; Lawrie, 1985). A cor é a primeira impressão que o consumidor tem de qualquer produto cárneo (Boakye \& Mittal, 1996).

A qualidade da carne está intimamente ligada à deposição de gordura que ocorre durante o crescimento do animal. A quantidade dessa deposição irá determinar a espessura de gordura subcutânea final, que é um dos principais parâmetros para avaliar a carcaça bovina e ponto de referência para classificação e pagamento da carcaça nos principais frigoríficos brasileiros (Rocha, 1999). A presença da gordura na carne, normalmente, não é desejável para o consumo humano, já que ela está relacionada a doenças coronarianas. Além disso, a deposição de gordura no processo de crescimento é energeticamente dispendiosa (Grant \& Helferich, 1991). Por outro lado, nas últimas três décadas, a gordura subcutânea ou de cobertura vem sendo enfatizada como um importante indicador na qualidade final da carne, uma 
vez que afeta a velocidade de resfriamento da carcaça, funcionando como um isolante térmico e interferindo positivamente na conversão de músculo em carne para o consumo humano (Felício, 1997).

A busca por uma metodologia simples e barata, que possa estimar com precisão a composição da carcaça de bovinos, levou pesquisadores a usarem diversos cortes da carcaça para estimar a sua composição, e depois de alguns trabalhos pioneiros foi proposto o uso do corte das 9-10-11 a costelas, separando fisicamente músculo, gordura e ossos, evitando, assim, maior depreciação da carcaça (Alleoni, 1995).

Hopper (1944) observou que a composição física do corte comercializável da costela, da parte comestível e da porção comestível das 9-10-11 a costelas era altamente correlacionado com a composição física e a porção comestível da carcaça.

O Brasil produz anualmente 12 milhões de toneladas de bagaço ou $30 \%$ da produção de cana-deaçúcar, das quais 4,8 milhões não são reutilizadas pela indústria, podendo servir como alimentação para ruminantes (Fapesp, 1998). Por se tratar de um subproduto muito barato, em relação a outros volumosos usados em confinamento (FNP/Boviplan, 1997), e rico em fibra bruta (Preston, 1995), pode ser usado nesse tipo de dieta.

Neste trabalho, procurou-se avaliar as características e a composição física de carcaça em tourinhos alimentados com dietas de alto concentrado com diferentes níveis de bagaço de cana-de-açúcar não tratado como volumoso.

\section{Material e Métodos}

O experimento foi realizado no Setor de Bovinocultura de Corte da Faculdade de Zootecnia e Engenharia de Alimentos (FZEA), da Universidade de São Paulo, campus de Pirassununga. Foram utilizados 36 animais machos inteiros oriundos de cruzamentos entre Bos taurus taurus na proporção de $3 / 4$ de sangue com Bos taurus indicus na proporção de $1 / 4$ de sangue. As raças paternas utilizadas foram a Continental (Gelbvieh) e a Britânica (Shorthorn), sendo as vacas mestiças Caracu x Nelore. Os animais foram divididos em dois grupos: a) 18 filhos de touros Continental (Gelbvieh); b) 18 filhos de touros Britânico (Shorthorn).

O experimento foi dividido em duas fases: período de adaptação de 42 dias, durante o qual os animais receberam alimentação balanceada com porções decrescentes de volumosos até atingir por volta de $20 \%$ na matéria seca (MS), e período experimental de 138 dias, durante o qual os animais foram alimentados com dieta de alto concentrado balanceada pelo CNCPS (Cornell Net Carbohydrate and Protein Syustem) com três diferentes níveis de bagaço de cana-de-açúcar in natura (BIN): 9, 15 e $21 \%$ na MS (Tabela 1 ).

As pesagens foram realizadas no início do período de adaptação, no início do período experimental e cada 28 dias, sempre em jejum hídrico e alimentar de 18 horas, inclusive antes do abate.

Após o abate, as carcaças foram esfoladas pelo método tradicional de tracionamento mecânico por corrente. Foram retirados o fígado, os rins e a gordura da região inguinal e pélvica sendo posteriormente pesados.

Foram feitas medidas de temperatura e de $\mathrm{pH}$ das carcaças em dois diferentes tempos: uma hora após

Tabela 1 - Composição das dietas utilizadas no experimento (\% na MS)

Table 1 - Composition of diets utilized in the experiment (\% of DM)

Tratamentos

Treatments

\begin{tabular}{|c|c|c|c|}
\hline $\begin{array}{l}\text { Ingredientes } \\
\text { Ingredients }\end{array}$ & $\begin{array}{l}9 \% \mathrm{BIN} \\
9 \% \text { SCB }\end{array}$ & $\begin{array}{l}15 \% \mathrm{BIN} \\
15 \% S C B\end{array}$ & $\begin{array}{l}21 \% \mathrm{BIN} \\
21 \% S C B\end{array}$ \\
\hline Bagaço de cana & 9,0 & 15,0 & 21,0 \\
\hline $\begin{array}{l}\text { Sugar cane bagasse } \\
\text { Farelo de soja } \\
\text { Soybean meal }\end{array}$ & 8,5 & 9,6 & 10,3 \\
\hline $\begin{array}{l}\text { Soja extrusada } \\
\text { Extruded soybean meal }\end{array}$ & 4,5 & 4,5 & 4,5 \\
\hline $\begin{array}{l}\text { Milho moído } \\
\text { Grounded corn }\end{array}$ & 45,1 & 40,9 & 37,1 \\
\hline $\begin{array}{l}\text { Polpa cítrica } \\
\text { Citrus pulp }\end{array}$ & 31,0 & 27,9 & 25,1 \\
\hline $\begin{array}{l}\text { Cloreto de potássio } \\
\text { Potassium chloride }\end{array}$ & 0,1 & 0,1 & 0,1 \\
\hline $\begin{array}{l}\text { Salmineral } \\
\text { Mineral salt }\end{array}$ & 0,8 & 0,8 & 0,8 \\
\hline $\begin{array}{l}\text { Rumensin } \\
\text { Rumensin }\end{array}$ & 0,03 & 0,03 & 0,03 \\
\hline $\begin{array}{l}\text { Uréia } \\
\text { Urea } \\
\text { Nutrientes (estimados) } \\
\text { Nutrients (estimated) }\end{array}$ & 1,0 & 1,0 & 1,0 \\
\hline $\begin{array}{l}\text { Proteína bruta, \% } \\
\text { Crude protein }\end{array}$ & 14,6 & 14,6 & 14,5 \\
\hline $\begin{array}{l}\text { NDT, } \% \\
T D N\end{array}$ & 78,8 & 75,4 & 72,0 \\
\hline
\end{tabular}

SCB - Sugar cane bagasse. 
o abate e imediatamente após a retirada das carcaças da câmara fria.

Foi realizada a pesagem das carcaças quentes, sendo posteriormente levadas à câmara frigorífica, onde permaneceram por 24 horas em temperatura de $2{ }^{\circ} \mathrm{C}$. Após esse período, as carcaças foram novamente pesadas, e feitas novas leituras de $\mathrm{pH}$. As carcaças foram secionadas entre a $5^{\mathrm{a}}$ e a $6^{\mathrm{a}}$ costelas para a divisão entre traseiro e dianteiro, sendo posteriormente retirados os cortes das $9-10-11^{\mathrm{a}}$ costelas da meiacarcaça esquerda de cada animal para posterior separação e cálculo da composição física do corte, de acordo com a metodologia de Hankins \& Howe (1946), que consiste na pesagem do corte, separação visual com faca do músculo, da gordura e dos ossos, que são pesados separadamente para a realização dos cálculos de porcentagem de cada componente. Também foram retirados três bifes de aproximadamente $2,5 \mathrm{~cm}$ de espessura dos músculos Longissimus dorsi e Supraspinatus, que foram identificados e embalados a vácuo e submetidas a 0,7 e 14 dias de maturação, e após, congeladas a $-20^{\circ} \mathrm{C}$, para posterior análise da textura e da cor objetivamente.

Também foi feito o corte entre a $12^{\mathrm{a}}$ e a $13^{\mathrm{a}}$ costelas para mensuração da área de olho de lombo (AOL) e da espessura de gordura subcutânea (EGS).

As pesagens das meias-carcaças foram realizadas com balança suspensa. As leituras de AOL foram realizadas com a contagem $\mathrm{em} \mathrm{cm}^{2}$ pelo método do plástico quadriculado. As mensurações de EGS foram realizadas com utilização de paquímetro, sendo a medida tomada na terça parte da porção superior proximal da curvatura do músculo Longissimus dorsi. As mensurações de temperatura e $\mathrm{pH}$ foram feitas utilizando-se um medidor digital portátil de temperatura e $\mathrm{pH}$ no qual era acoplada uma sonda metálica para a leitura da temperatura e um eletrodo de perfuração de vidro para o $\mathrm{pH}$.

A análise da textura objetiva foi realizada de acordo com a metodologia proposta por Wheeler et al. (1995) e determinada pelo aparelho WarnerBratzler. A coloração foi determinada por meio do método colorimétrico (Miniscan XE - Hunterlab) imediatamente após o abate e antes da realização da análise da textura, após abertas as embalagens e a amostra submetida a 30 minutos de exposição ao ar. Foi realizada a análise da coloração somente do músculo Longissimus dorsi.

As análises estatísticas foram realizadas pelo procedimento GLM do programa SAS $\AA$ (1990).

\section{Resultados e Discussão}

Ao final do período de adaptação, os animais apresentavam idade média de 9 meses e $257 \mathrm{~kg}$, e 13 meses e $435 \mathrm{~kg}$ no momento do abate. Os dados referentes às pesagens durante o período experimental estão dispostos na Tabela 2.

Não foram observadas interações entre grupo genético e os tratamentos nutricionais para nenhuma das variáveis analisadas.

As medidas médias das características e a composição física das carcaças, além dos pesos das carcaças, estão detalhadas na Tabela 3.

Para a composição física do corte da $9-10-11^{a}$ costelas e todas as características de carcaça, não ocorreram diferenças significativas entre os tratamentos, com exceção da gordura renal e pélvica $(\mathrm{p}<0,05)$ para os tratamentos 9 e $15 \%$ em relação ao tratamento com $21 \%$ de BIN. Houve uma tendência $(p=0,10)$ para uma maior espessura de gordura subcutânea nos tratamentos com menor porcentagem de fibras (9 e 15\%). Estes resultados concordam com a literatura conforme mostram trabalhos publicados por Bergen et al. (1997) e Herring et al. (1994).

As características de carcaça observadas neste trabalho também são semelhantes às encontradas por Bartle \& Preston (1992a), Bartle \& Preston (1992b) e Bartle et al. (1994).

Os resultados mostraram que baixos níveis de fibras em dietas de alto concentrado não alteraram a composição física das carcaças de animais inteiros abatidos muito jovens. Isso sugere que animais adultos provavelmente apresentariam números diferentes. Porém os números deste trabalho são bastante semelhantes aos encontrados por Alleoni (1995), que

Tabela 2 - Médias dos pesos $(\mathrm{kg})$ dos animais por tratamento, durante o período experimental

Table 2 - Live weight mean $(\mathrm{kg})$ by treatment during the experimental period

\begin{tabular}{lccc}
\hline & \multicolumn{3}{c}{$\begin{array}{c}\text { Tratamentos } \\
\text { Treatments }\end{array}$} \\
\cline { 2 - 4 } Período, dias & $9 \%$ BIN & $15 \%$ BIN & $21 \%$ BIN \\
Period, days & $9 \%$ SCB & $15 \%$ SCB & $21 \%$ SCB \\
\hline 1 & 260,25 & 258,92 & 258,58 \\
28 & 298,75 & 304,42 & 290,92 \\
56 & 336,00 & 352,50 & 326,75 \\
84 & 370,00 & 388,67 & 366,00 \\
112 & 421,42 & 431,33 & 401,08 \\
139 & 430,75 & 448,33 & 424,75 \\
\hline
\end{tabular}


Tabela 3 - Características de carcaça, composição física do corte das $9-10-11^{\text {a }}$ costelas e peso das carcaças

Table 3 - Carcass traits, physical composition of 9-10-11 th ribs cut and carcass weight

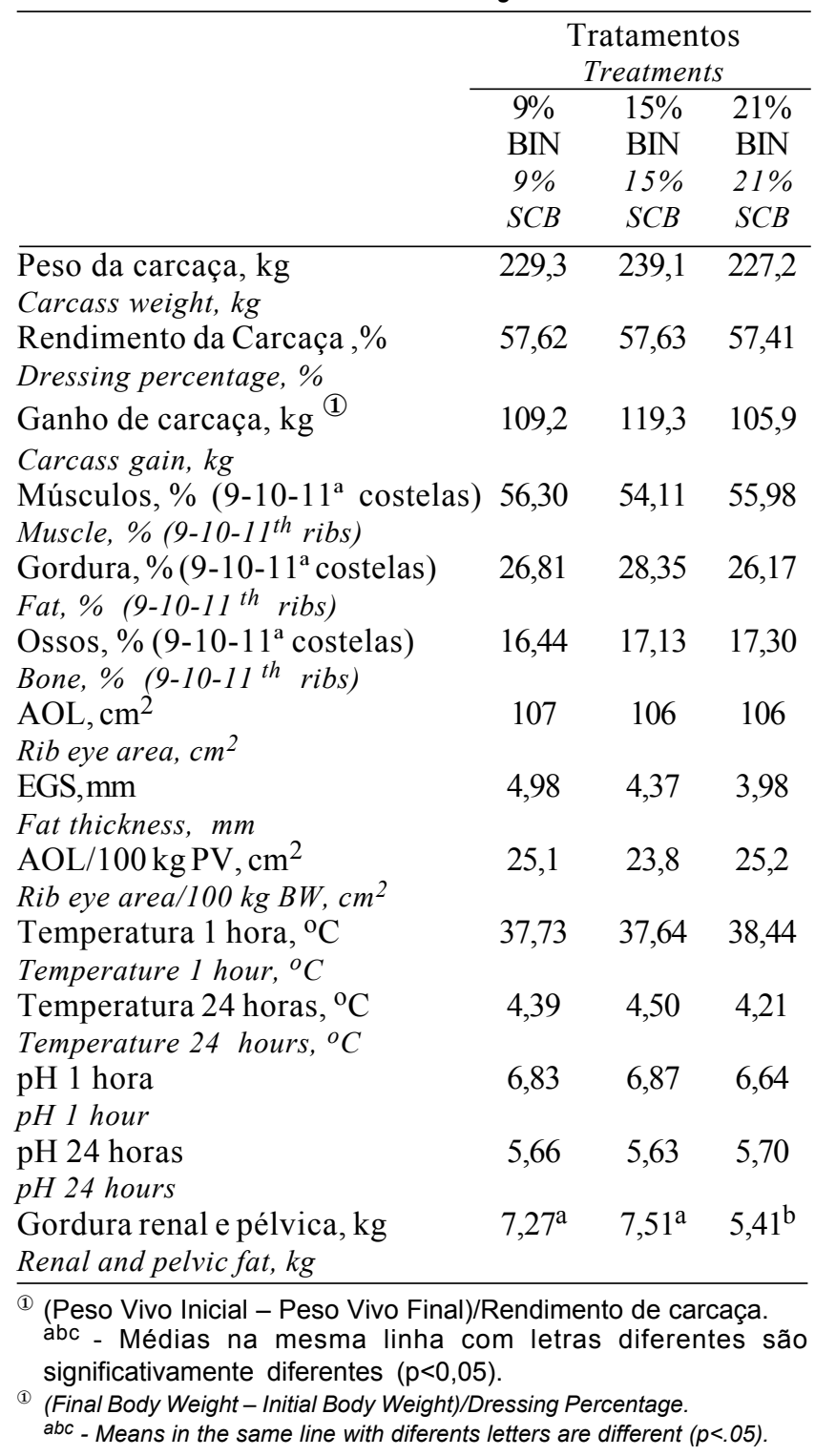

utilizou animais zebuínos castrados, com idade média de 25 meses.

A maior quantidade de gordura renal e pélvica nos tratamentos com maior porcentagem de energia (concentrado) é consistente com a literatura, no sentido de ocorrer maior deposição de gorduras nessa região.

As amostras dos músculos Supraspinatus e Longissimus dorsi, maturadas por 0, 7 ou 14 dias, foram testadas no aparelho Warner-Bratzler quanto a sua força de cisalhamento, e os resultados são representados na Tabela 4.
Tabela 4 - Médias de força de cisalhamento $(\mathrm{kg})$, dos músculos L. dorsi e Supraspinatus, nos diferentes tempos de maturação

Table 4 - Means of Warner-Bratzler shear force $(\mathrm{kg})$ of $\mathrm{L}$. dorsi and supraspinatus muscles, at different time of maturation

\begin{tabular}{lcccccc}
\hline & \multicolumn{5}{c}{$\begin{array}{c}\text { Tempo de maturação (dias) } \\
\text { Time of maturation (days) }\end{array}$} \\
\cline { 2 - 7 } $\begin{array}{l}\text { Tratamento } \\
\text { Treatment }\end{array}$ & $\begin{array}{c}\text { Supraspinatus } \\
\text { Longissimus dorsi }\end{array}$ \\
\hline & 0 & 7 & 14 & 0 & 7 & 14 \\
\hline $9 \%$ BIN & 5,31 & 4,07 & 4,01 & 7,87 & 6,56 & 4,17 \\
$9 \%$ SCB & 4,41 & 3,68 & 3,69 & 7,72 & 5,32 & 3,77 \\
$15 \%$ BIN & & & & & & \\
$15 \%$ SCB & 4,68 & 3,57 & 3,51 & 6,61 & 4,71 & 3,81 \\
$21 \%$ BIN & & & & & & \\
$21 \%$ SCB & & & & & &
\end{tabular}

A textura objetiva (WB) foi diferente $(\mathrm{p}<0,05)$ entre os três grupos de bifes maturados nos dois músculos testados; o grupo de tempo 14 foi mais macio que o tempo 7, e este, mais macio que o tempo 0 . Não ocorreram diferenças significativas para força de cisalhamento entre os tratamentos. Esses resultados mostram a eficiência do método de maturação a vácuo, como afirmaram Kastner \& Felício (1980), pois a diminuição na força de cisalhamento ficou evidente.

Corte (1980) e Luchiari Filho et al. (1981) encontraram valores menores na força de cisalhamento que os deste trabalho para o Longissimus dorsi. Junqueira (1996) também encontrou valores menores para força de cisalhamento no músculo Longissimus dorsi, porém encontrou resultados semelhantes para o músculo Supraspinatus. Provavelmente esses valores ocorreram devido ao maior peso das carcaças e da maior espessura de gordura subcutânea nesses animais em comparação com os deste trabalho. Neste experimento, o músculo Supraspinatus, comercialmente classificado como carne de segunda, foi mais macio que o músculo Longissimus dorsi (carne de primeira), o que sugere que com o resfriamento carcaças pequenas e com pouca cobertura de gordura estarão mais sujeitas aos efeitos do resfriamento na sua porção superficial.

Quanto à coloração, não ocorreram diferenças significativas entre os tratamentos nos diferentes músculos (Tabelas 5 e 6). Estes resultados estão de acordo com os de Loxton (1993), que concluiu que o manejo alimentar tem pouca influência na cor de cortes frescos. 
As médias encontradas no músculo Longissimus dorsi para a variável L* (Luminosidade) foram superiores às mostradas por Loxton (1993), cujos valores foram de 34,42 em animais semelhantes aos deste experimento. Entretanto Junqueira (1996), trabalhando também com animais cruzados, encontrou valores semelhantes aos deste trabalho. Purchas (1988) definiu para a luminosidade $\left(\mathrm{L}^{*}\right)$ valores ideais entre 34 e 39, e para a intensidade da cor vermelha ( $\left.\mathrm{a}^{*}\right)$, entre
18 e 22. Para a variável a*, os valores obtidos neste trabalho foram inferiores aos considerados ideais.

Houve efeito significativo para o período de maturação. A carne maturada (tempos 7 e 14) foi mais macia e brilhante, e suas cores, mais realçadas $(\mathrm{p}<0,05)$. Essa variação está de acordo com a obtida por Boakye \& Mittal (1996), que demonstraram que o tempo de maturação teve influência em todos os parâmetros de cor.

Tabela 5 - Médias dos parâmetros de cor do músculo Supraspinatus, nos diferentes períodos de maturação Table 5 - Means of color parameters of Supraspinatus muscle at different periods of maturation

\begin{tabular}{|c|c|c|c|c|c|c|c|c|c|}
\hline \multirow{3}{*}{$\begin{array}{l}\text { Tratamento } \\
\text { Treatments }\end{array}$} & \multicolumn{9}{|c|}{$\begin{array}{c}\text { Tempo de maturação (dias) } \\
\text { Time of maturation (days) }\end{array}$} \\
\hline & \multicolumn{3}{|c|}{0} & \multicolumn{3}{|c|}{7} & \multicolumn{3}{|c|}{14} \\
\hline & $\mathrm{L}^{*}$ & $\mathrm{~A}^{*}$ & $\mathrm{~B}^{*}$ & $\mathrm{~L}^{*}$ & $\mathrm{~A}^{*}$ & $\mathrm{~B}^{*}$ & $\mathrm{~L}^{*}$ & $A^{*}$ & $\mathrm{~B}^{*}$ \\
\hline $\begin{array}{l}9 \% \text { BIN } \\
9 \% \text { SCB }\end{array}$ & 37,02 & 14,66 & 11,18 & 37,38 & 16,36 & 12,78 & 40,02 & 16,01 & 13,65 \\
\hline $\begin{array}{l}15 \% \mathrm{BIN} \\
15 \% \text { SCB }\end{array}$ & 37,79 & 14,80 & 11,66 & 38,75 & 15,96 & 12,88 & 40,55 & 15,59 & 13,62 \\
\hline $\begin{array}{l}21 \% \mathrm{BIN} \\
21 \% S C B \\
\end{array}$ & 36,60 & 14,95 & 11,51 & 37,20 & 16,03 & 12,48 & 39,32 & 15,04 & 12,79 \\
\hline
\end{tabular}

$\mathrm{L}^{*}$ - Luminosidade (Luminosity).

$A^{*}$ - Intensidade da cor vermelha (Red color intensity).

$\mathrm{B}^{*}$ - Intensidade da cor amarela (Yellow color intensity).

Tabela 6 - Médias dos parâmetros de cor do músculo Longissimus dorsi, nos diferentes períodos de maturação Table 6 - Means of color parameters of Longissimus dorsi muscle at different periods of maturations

\begin{tabular}{|c|c|c|c|c|c|c|c|c|c|}
\hline \multirow{3}{*}{$\begin{array}{l}\text { Tratamento } \\
\text { Treatments }\end{array}$} & \multicolumn{9}{|c|}{$\begin{array}{l}\text { Tempo de maturação (dias) } \\
\text { Time of maturation (days) }\end{array}$} \\
\hline & \multicolumn{3}{|c|}{0} & \multicolumn{3}{|c|}{7} & \multicolumn{3}{|c|}{14} \\
\hline & $\mathrm{L}^{*}$ & $A^{*}$ & $\mathrm{~B}^{*}$ & $\mathrm{~L}^{*}$ & $A^{*}$ & $\mathrm{~B}^{*}$ & $\mathrm{~L}^{*}$ & $\mathrm{~A}^{*}$ & $\mathrm{~B}^{*}$ \\
\hline $\begin{array}{l}9 \% \mathrm{BIN} \\
9 \% \text { SCB }\end{array}$ & 37,16 & 15,19 & 11,61 & 38,20 & 17,28 & 13,77 & 40,40 & 16,02 & 14,35 \\
\hline $\begin{array}{l}15 \% \mathrm{BIN} \\
15 \% \text { SCB }\end{array}$ & 36,66 & 15,95 & 12,02 & 38,37 & 17,69 & 14,00 & 40,07 & 16,63 & 14,54 \\
\hline $\begin{array}{l}21 \% \mathrm{BIN} \\
21 \% S C B\end{array}$ & 37,15 & 15,53 & 11,98 & 38,86 & 17,03 & 13,64 & 39,40 & 16,10 & 13,96 \\
\hline
\end{tabular}

$L^{*}$ - Luminosidade (Luminosity).

$A^{*}$ - Intensidade da cor vermelha (Red color intensity).

$\mathrm{B}^{*}$ - Intensidade da cor amarela (Yellow color intensity).

\section{Conclusões}

Dietas com 9, 15 ou $21 \%$ de bagaço de canade-açúcar in natura e elevada proporção de concentrado não alteraram a composição física e as características qualitativas da carcaça de tourinhos cruzados. Apesar de baixa cobertura de gordura, obteve-se uma carne macia, após a maturação, e sem diferenças entre os tratamentos. O músculo Supraspinatus, apesar de sua localização anatômica, é mais macio que o músculo Longissimus dorsi, realçando a importância da maturação e a possibilidade de valorização de um corte pouco explorado comercialmente. 


\section{Literatura Citada}

ALLEONI, G.F. Avaliação da gravidade específica da carcaça, da composição química e física, dos cortes da costela para estimar a composição corporal de novilhos Nelore na fase de acabamento. Jaboticabal: Universidade Estadual Paulista, 1995. Tese (Doutorado em Zootecnia) - Universidade Estadual Paulista, 1995.

BARTLE, S.J.; PRESTON, R.L.; MILLER, M.F. Dietary energy source and density: Effects of roughage source roughage equivalent, tallow level, and steer type on feedlot performance and carcass characteristics. Journal of Animal Science, v.72, n.8, p.1943-1953, 1994

BARTLE, S.J.; PRESTON, R.L. Roughage level and limited maximum intake regimes for feedlot steers. Journal of Animal Science, v.70, n.11, p.3293-3303, 1992a.

BARTLE, S.J.; PRESTON, R.L. Limited maximum intake, reduced roughage regime and steam-flaked sorghum grain, roughage level, and feeding regime for feedlot steers. (Agriculture Science Technical Report, T-5-317), Lubbock: Texas Technical University, p.128-133. 1992b.

BARTLE, S.J.; PRESTON.; R.L. Dietary roughage regime for feedlot steers: reduced roughage level $(2 \%)$ during the midfinishing period. Journal of Animal Science, v.69, n.9, p.3461-3466, 1991.

BERGEN, R.D.; McKINNON, J.J.; CHRISTENSEN, D.A. et al. Use of real-time ultrasound to evaluate live animal carcass traits in young performance-tested beef bulls. Journal of Animal Science, v.75, n.9, p.2300-2307, 1997.

BOAKYE, K.; MITTAL, G.S. Changes in colour of beef M. longissimus dorsi. Muscle during ageing. Meat Science, v.42, p.347-354, 1996.

BULLE, M.L.M.; RIBEIRO, F.G.; LEME, P.R. et al. Uso do Bagaço de cana-de-açúcar como único volumoso em dietas de Alto Teor de Concentrado. 1. Desempenho. In: REUNIÃO ANUAL DA SOCIEDADE BRASILEIRA DE ZOOTECNIA, 36., 1999, Porto Alegre. Anais... Porto Alegre: Sociedade Brasileira de Zootecnia, 1999. p.306.

CIA, G.; CORTE, O.O. Influência da velocidade de resfriamento na maciez da carne bovina. In: SEMINÁRIO NACIONAL DE ARMAZENAGEM, 3., 1978. Anais... Curitiba: 1978.

COMMISSION INTERNATIONALE DE ECLAIRAGE - CIE. Colorimetry. 2.ed. Viena, 1976. (CIE Publications, 15.2)

CORTE, O.O. Composição e Qualidade de Carne de Tourinhos Nelore, Chianina x Nelore e Marchigiana x Nelore. Campinas. Boletim Técnico do Centro de Tecnologia da Carne, v.5, p.1-10, 1980.

FAPESP. Propriedades do bagaço da cana-de-açúcar. Notícias: 1998. p.12.

FELÍCIO, P.E. Fatores ante e post-mortem que influenciam na qualidade da carne vermelha. In: REUNIÃO ANUAL DA SOCIEDADE BRASILEIRA DE ZOOTECNIA, 30., 1993, Rio de Janeiro. Anais... Rio de Janeiro: Sociedade Brasileira de Zootecnia, 1993. p.43-52.

FELÍCIO, P.E. Fatores ante e post mortem que influenciam na qualidade da carne bovina. In: PEIXOTO, A.M.; MOURA, J.C.; FARIA, V.P. (Eds.) Produção do novilho de corte. Piracicaba: Fundação de Estudos Agrários "Luiz de Queiroz", 1997. p.79-97.
FELÍCIO, P.E. Qualidade da carne bovina: características físicas e organolépticas. In: REUNIÃO ANUAL DA SOCIEDADE BRASILEIRA DE ZOOTECNIA, 36., Porto Alegre, 1999. Anais... Porto Alegre: Sociedade Brasileira de Zootecnia, 1999. p.89-97.

FNP/BOVIPLAN. Custo de produção de silagens - Anuário da Pecuária Brasileira (ANUALPEC 97). São Paulo: Argos, 1997. p.194.

GALYEAN, M.L. Protein levels in beef cattle finishing diets: industry application, university research, and system results. Journal of Animal Science, v.74, n.11, p.2860-2870, 1996.

GRANT, A.L.; HELFERICH, W.G. Overview of growth. In: PEARSON, A.M.; DUTSON, T.R. (Eds.) Growth regulation in farm animals. New York: Kluwer, 1991. p.7-11.

HANKINS, O.G.; HOWE, P.E. Estimation of the composition of beef carcass and cuts. Washington: USDA, 1946. (Tech. Bulletin - USDA).

HERRING, W.O.; WILLIANS, S.E.; BERTRAND, J.K. et al. Comparison of live and carcass equations predicting percentage of cutability, retail product weight, and trimmable fat in beef cattle. Journal of Animal Science, v.72, n.5, p.1.107$1.118,1994$.

HOPPER, T.H. Methods of stimating the physical and chemical composition of cattle. Journal of Agriculture Research, v.68, n.6, p.239-268, 1944.

JUNQUEIRA, L.O.B. Qualidade das carcaças de bovinos jovens, machos e fêmeas, cruzados Marchigiana vs. Nelore, terminados em confinamento. Pirassununga-SP, 1996. 56p. Dissertação (Mestrado em Zootecnia) - Universidade de São Paulo, 1996.

KASTNER, C.L.; FELÍCIO, P.E. Tratamentos que influem na maciez da carne bovina no período pós-abate. Boletim Técnico do Centro de Tecnologia da Carne, v.5, p.1-10, 1980.

KOOHMARAIE, M.; SHACKELFORD, S.D.; WHEELER, T.L. A base biológica da maciez da carne bovina e abordagens potenciais para seu controle e previsão. In: REPENSANDO A PECUÁRIA DE CORTE: EXPERIÊNCIAS INTERNACIONAIS, 1998, São Paulo. Anais... Uberaba: Pinti, 1998. p.94-139.

KOOHMARAIE, M.; WHEELER, T.L.; SHACKELFORD, S.D. Beef tenderness: regulation and prediction. Nebraska:US Meat Animal Research Center, 1994. 11p.

LAWRIE R.A. Meat science. 4.ed. New York: Pergamon Press, 1985. $451 \mathrm{p}$.

LOXTON, I. D. The influence of animal nutrition on the quality of meat from Bos indicus cross-bred steers in Northern Australia. In: THE AUSTRALIAN MEAT INDUSTRY RESEARCHCONFERENCE, Australia, 1993. Proceedings... Australia: CSIRO, 1993. p.1-13.

LUCHIARI FILHO, A.; BOIN, C. ; MARCONDES, C. et al. Estudo comparativo das características de carcaça de tourinhos Nelore, meio-sangue Marchigiana vs Nelore e meio-sangue Chianina vs Nelore. Boletim da Indústria Animal, v.38, n.1, p.9-17, 1981.

LUCHIARI FILHO, A.; MOURA, A.C. Situação atual e tendências da pecuária de corte no Brasil relacionada à qualidade da carne. In: SIMPÓSIO INTERNACIONAL SOBRE PRODUÇÃO INTENSIVA DE GADO DE CORTE, 1., 1997, São Paulo. Anais... São Paulo: 1997. p.42-44. 
PRESTON, R.L. Management of high concentrate diets in feedlot. In: SIMPÓSIO SOBRE PRODUÇÃO INTENSIVA DE GADO DE CORTE, Campinas: Colégio Brasileiro de Nutrição Animal, 1998. p.82-91.

PRESTON, R.L. Mechanically programmed feeding system and application: step-up programs. In: OWENS, F.; GILL, K. et al. (Eds.) Symposium: Intake by feedlot cattle, 1995. Local: Proceedings... Oklahoma: Oklahoma Agriculture Experimentation Station, Division of Agriculture Science Natural Research, Ok State University, Still Water, 1995. p.181-184.

PURCHAS, R.W. Some experiences with dark-cuting beef in New Zealand. In: AUSTRALIAN WORKSHOP. AUSTRALIAN MEAT AND LIVE-STOCK RESEARCH AND DEVELOPMENT CORPORATION, 1988, Sydney. Anais... Sydney, 1988. p.42-51.

ROCHA, C.E. Fatores que influenciam características e valor da carcaça em um rebanho de bovinos da raça Nelore. Jaboticabal: Universidade Estadual Paulista, 1999. 95p. Dissertação (Mestrado em Zootecnia) - Universidade Estadual Paulista, 1999.
SAS INSTITUTE. SAS/STAT User's Guide, Version 6.4 ed., Cary: 1990. v.2.

SEIDEMAN, S.C.; CROSS, H.R.; SMITH, G.C. et al. Color in the meat ageing. Journal of Food Quality, v.6, p.211, 1984.

WHEELER, T.L.; KOOHMARAIE, M.; SHACKELFORD, S.D. Standardized Warner-Bratzler shear force procedures for meat tenderness measurement (Online). Available URL: http://192.133.74.26/MRU_WWW/protocol/WBS.html. 1995.

WELLINGTON, G.H.; STOUFFER, J.R. Beef marbling: its estimation and influence on tenderness and juiciness. New York: State College of Agriculture - Cornell University, 1959. 30p.

Recebido em:25/05/01

Aceito em: 08/11/01 